\title{
Assessment of General Characteristics of Geriatric Patients Admitted in a Tertiary Care Teaching Hospital
}

\author{
Thennarasu Palani', Ramakrishnan V Trichur², Selina Grace Kurian', Selvabharathi M¹, \\ Sivashankari $\mathbf{M}^{1}$, Shalini AS $^{1}$, Srikanth Jeyabalan ${ }^{3, *}$
}

${ }^{1}$ Department of Pharmacy Practice, Sri Ramachandra Faculty of Pharmacy, Sri Ramachandra Institute of Higher Education and Research (DU), Porur, Chennai, Tamil Nadu, INDIA.

2Department of Emergency Medicine, Sri Ramachandra Medical college and Research Institute, Porur, Chennai, Tamil Nadu, INDIA. ${ }^{3}$ Department of Pharmacology, Sri Ramachandra Faculty of Pharmacy, Sri Ramachandra Institute of Higher Education and Research (DU), Porur, Chennai, Tamil Nadu, INDIA.

\begin{abstract}
Aim/Background: The study aims to identify the risk profile of patients aged above 65 years and to study the pattern of drug use and resource planning for interventions. Methods and Materials: A prospective observational study was conducted in the Department of Emergency and Critical Care, Sri Ramachandra Institute of Higher education and Research that offers health care services in Porur, Chennai. Eighty-four patients were watched during the study period of 6 months. After providing written and oral information, written informed consent or proxy content was obtained from every participant before inclusion. Results: We characterized adults older than 65 years attending the ED in urban tertiary health care teaching hospital and observed several parameters like demographic variables, admission and discharge details, Prolonged Length of Stay (LOS), reasons for admission to Emergency Department, diagnosis, comorbidities, polypharmacy and final disposition. Conclusion: The rate of hospitalization and the rate of admissions were higher for the geriatric population when compared to younger adults in the Emergency Department. These rates increased with increasing age, presence of comorbidities and acute illness severity. In our study, disorders of the circulatory system were the leading cause that led to admission, hospitalization and mortality of the elderly.
\end{abstract}

Key words: Prospective, Observational study, Risk profile, Drug use, Comorbidity, Hospitalization.

\section{INTRODUCTION}

The commencement of old age or life expectancy cannot be defined as it does not seize the same sense in all societies. People can be considered old because of specific changes in their activities, lifestyles, environment and other social roles. In January 1999, 'National Policy on Older Patients' was adopted by the Government of India, which demarcates people as 'senior citizen' or 'elderly' who are 60 years old or above. ${ }^{1}$ Aging indicates that it involves a continual process, which results in impaired structure and function, weakening of the immune system, susceptibility to various diseases and reduced reproductive capacity. ${ }^{2}$ Geriatrics simply refers to the medical care of older people that has attracted unprecedented attention and rightly. Gerontology contrariwise refers to the "study of physical and psychological variations which are incident to old age." Investigational gerontology is concerned with research into the underlying biological problems of aging, en route towards physiology, biochemistry, pathology and psychology. ${ }^{3}$ Clinical gerontology is concerned with research that characterizes physiological changes across the human lifespan that influence the risk of agerelated conditions. ${ }^{4}$ Ageing populations have brought with them a myriad of socioeconomic and medical problems, tackling which has become a significant concern of governments all around the world. Due to the demographic, social and economic shift in India, young people often migrate
DOI: 10.5530/ijopp.14.2.17

Address for correspondence: Dr. Srikanth Jeyabalan, Assistant Professor, Department of Pharmacology, Sri Ramachandra Faculty of Pharmacy, Sri Ramachandra Institute of Higher and Research (DU), Porur, Chennai-600116, Tamil Nadu, INDIA.

Phone no: +919094020093 Email Id: srikanth.j@ sriramachandra.edu.in

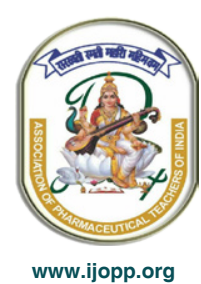


to urban areas, which pushes older people to live alone. Also, the elderly population is increasing rapidly. So, quality medical and social care is a requirement for their survival. However, due to unsupportive attitudes, limited awareness, inadequate knowledge and nonacceptance of geriatrics as an established discipline, it results in inaccessible and poor-quality care for India's old.

In India, older people suffer from both communicable as well as non-communicable diseases. One out of two elderly in India suffers from at least one chronic disease which requires long-term medication, which is further worsened by the impairment of special sensory functions like vision and hearing. Due to the age-related physiological, lifestyle and immunological changes, communicable diseases have far spread among older people. The prevalence of Tuberculosis (TB) is higher among the elderly than younger individuals. According to statistics by the Government of India, one-third of elderly mortality is dues to cardiovascular disorders, $10 \%$ for respiratory disorders and infections, including TB $(10 \%)$. The root of elderly mortality includes nutritional, metabolic deficiency, gastrointestinal and genitourinary infections, among which neoplasm accounts $6 \%$ and accidents, poisoning, violence add up to $4 \%$. As per the 2011 census, most common disabilities among the aged were locomotor and visual; almost half of the elderly disabled population found to be suffering from these two types of disabilities. ${ }^{5} \mathrm{~A}$ recent report published on morbidity profiles by the Indian Council of Medical Research (ICMR) finds that hearing impairment was the most common morbidity along with visual impairment among the older people in India. ${ }^{6}$ Similarly, another study conducted in Tamil Nadu reported that arthritis was the most common morbidity among the participants at the rate of $43.4 \%$. Further morbidities were hypertension (HTN) (14\%), diarrhea $(12 \%)$, chronic cough $(12 \%)$, skin diseases $(12 \%)$, heart illness $(9 \%)$, diabetes $(8.1 \%)$, asthma $(6 \%)$ and urinary problems (5.6\%)..$^{7}$ A cross-sectional study conducted in the rural area of Karnataka found that $33.9 \%$ of the geriatric population in the selected province was above the threshold for mental illness based on the General Health Questionnaire-12 (GHQ-12). A psychiatric disorder like depression $(21.9 \%)$ and anxiety was most prevalent among the study population $(10.7 \%)$. The prevalence of cognitive impairment was significantly high over the affected individuals in the $80+$ age group. ${ }^{8}$ The socio-economic conditions of a given population varies widely in different parts within the country, which is why different studies conducted in various parts of the country are unlikely to yield non-uniform results. Emergency Departments (EDs) plays an essential role in the care of older adults. ${ }^{9-11}$ A study comparing the ED usage in the US and Canada found similarly high visit rates for patients over 75 years in Ontario (73.1 per 100 of the population)..$^{12}$ EDs provide essential care and service to older adults, often aiding as a pointof-entry to the hospital, long-term care and providing after-hours care to those unable to access a primary care provider. ${ }^{13,14}$ Addressing the complex care needs of older adults in an ED setting, it is likely to place increased strain on a system that is already burdened with overcrowding. So, researchers have focused on older adult ED usage, with the strategy to provide good ED care that meets the particular needs of this population. ${ }^{15-17}$

Elderly patients ( $\geq 65$ years) use the ED more frequently over the years and are more prone to experience adverse health follow-up, like hospitalization, prolonged hospital stay, functional decline and mortality than younger patients. ${ }^{18-21}$

EDs are playing an increasingly important role in the care of older adults. In the United States, patients older than 75 years have the highest $E D$ visit rates after infants less than one year of age. ${ }^{22}$

A forementioned study suggests that older patients presenting to the ED differ from younger patients in several important ways. ${ }^{23}$ Older adults are often more acutely ill than younger patients. ${ }^{24}$ They are also likely to have a more extended stay in the ED and hospitalized following to their visit. ${ }^{25,26}$ In Canada, patients admitted following their ED visit are approximately half (47.1\%) over the age of 65 years. ${ }^{27}$ A survey from the United States reports increased resource use intensity among older adults who visit the ED in the form of increased admissions, use of Intensive Care Unit (ICU) services, imaging and use of laboratory services. ${ }^{28}$ Older adults who are often visiting the ED address about congestive heart failure, ischemic heart disease, cardiac dysrhythmias, abdominal disorders, acute cerebrovascular accidents, syncope, pneumonia and urinary tract infections (UTI). ${ }^{29}$ Though numerous studies have reported on ED usage by older adults, relatively few have focused upon the south Indian populations. Hence, this study aims to characterize the population of older South Indians seeking care in the ED and to add to the current body of literature by providing a detailed description of primary diagnosis and resource use intensity.

\section{MATERIALS AND METHODS}

\section{Study design and patient selection}

A prospective observational study was conducted in 
the Department of Emergency and Critical Care, Sri Ramachandra Institute of Higher education and Research (Deemed to be University) that offers health care services in Porur, Chennai. Overall, 84 patients were observed during the study period of 6 months. After providing written and oral information, written informed consent or proxy content (i.e., by next of kin) was obtained for every participant before inclusion.

\section{Patient selection criteria}

\section{Inclusion criteria}

Patient aged greater than 65 years with medical or surgical issues was considered as the inclusion criteria for selection of this study.

\section{Exclusion criteria}

Patients aged lesser than 65 years or those referred for trauma will be excluded. Patients who had received pre-hospitalized cardiopulmonary resuscitation and are transferred to other hospitals than the study centers.

\section{Design and variables of the study}

The population of the study included all patients belonging to the age group 65 years or above who visited the ED from October 2018 to January 2019. For the study, patients aged 65 years to 74 years are categorized as younger elderly. Whereas, patients aged more than 75 years were classified or represented as older elderly. The variables observed can be classified as demographic variables, admission variables and followup variables. The variables of the study are age, gender, admission and discharge details, LOS, which defines as from the time of patient registration until the time the patient leaves the hospital. LOS also excludes visits lasting 15 min or less, reasons for admission, Final Diagnosis, presence of comorbidities, polypharmacy and final disposition.

\section{Statistical analysis}

Categorical data represented as numbers and percentages. Mean values are reported for age and length of stay at hospital. The data evaluation and graphs was created by using Microsoft excel.

\section{Ethical approval}

The study was reviewed and approved by the Ethics Committee for Students Proposal, Sri Ramachandra Institute of Higher Education and Research, Porur. As per advice, the ICMR guidelines of Biomedical Research in Human Beings and Good Clinical Practices were followed. CSP/18/SEP/73/280 dated 22/10/2018

\section{RESULTS}

\section{Gender distribution of the study population}

Among 125 patients that were observed, 84 patients were found to be 65 years and above $56(66.7 \%)$ patients belonged to the male gender and $28(33.3 \%)$ patient belonged to the female gender. The minimum age of patient was identified as 66 and maximum age of patient was found to be 89 years with a Mean \pm SD value $(72.77 \pm 5.54)$. The length of stay at hospital was found to be for a minimum of 1 day and maximum of 26 days with a Mean \pm SD value of $(4.76 \pm 4.44)$ for a total sample size of $n=84$.

\section{Distribution of geriatric patients admitted in ED according to age group}

The elderly population admitted to the ED was further grouped into different age groups. $56(66.7 \%)$ patients belonged to the age group of $65-74$ years, $23(27.4 \%)$ in the age group of 75-84 years and five patients were found to be more than 84 years old.

\section{Age group-wise gender distribution of elderly patients admitted to the ED}

Of all the patients admitted in the ED, 45.6\% male and $21.6 \%$ female belonged to the age group of $65-74$ years and $18 \%$ male and $9.6 \%$ female were recognized under the age group of 75-84 years. Comparatively, a smaller number of male $(3.6 \%)$ and female $(2.4 \%)$ patients admitted were found to be above 85 years and represented in Table 1.

\section{Reason of admission of geriatric population in the ED}

Most of the patients admitted to the ED with the major complaints. Reasons were Shortness of Breath (32.4\%), fever (9.6\%), Abdominal Pain (6\%), Acute gastroenteritis (3.6\%), Headache $(1.2 \%)$, Chest Pain $(12 \%)$, Decreased Responsiveness (4.8\%), Musculoskeletal Issues (22.8\%), Giddiness (4.8\%), for diabetes control (1.2\%), Burning micturition $(1.2 \%)$ and change in color of the foot $(1.2 \%)$.

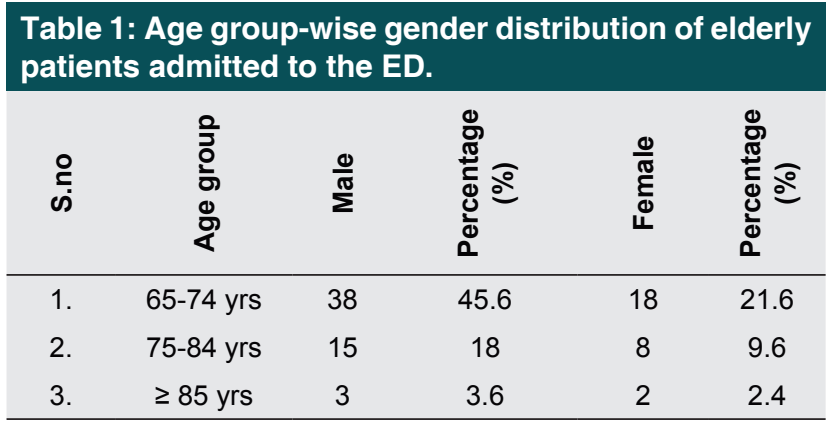

Values are expressed as percentage values for male and female patients for a sample of $n=84$ 


\begin{tabular}{|c|c|c|c|}
\hline S.no & $\begin{array}{l}\text { Reason for admission of } \\
\text { geriatric patients }\end{array}$ & $\begin{array}{l}\text { No. of } \\
\text { patients }\end{array}$ & $\begin{array}{l}\text { Percentage } \\
(\%)\end{array}$ \\
\hline 1 & Shortness of breath & 27 & 32.4 \\
\hline 2. & Fever & 8 & 9.6 \\
\hline 3. & Abdominal Pain & 5 & 6 \\
\hline 4. & Acute gastroenteritis & 3 & 3.6 \\
\hline 5. & Headache & 1 & 1.2 \\
\hline 6. & Chest Pain & 10 & 12 \\
\hline 7. & $\begin{array}{c}\text { Decreased } \\
\text { Responsiveness }\end{array}$ & 4 & 4.8 \\
\hline 8. & Musculoskeletal & 19 & 22.8 \\
\hline 9. & Giddiness & 4 & 4.8 \\
\hline 10. & Diabetes control & 1 & 1.2 \\
\hline 11. & Burning Micturition & 1 & 1.2 \\
\hline 12. & Change in color of the foot & 1 & 1.2 \\
\hline
\end{tabular}

Values are expressed as percentage values for number of patients for a sample of $n=84$

The results were tabulated in Table 2 .

\section{The final diagnosis of elderly patients admitted in the ED}

As observed in every other study, the most frequently observed final diagnosis was found to be cardiovascular disease (CVD) (28.8\%), followed by stroke (13.2\%), COPD (13.2\%), diabetes mellitus (DM) $(13.2 \%)$, pneumonia $(6 \%)$, heart failure $(4.8 \%)$, UTI $(4.8 \%)$, renal failure (4.8\%), acute gastroenteritis $(2.4 \%)$, asthma $(1.2 \%)$, hepatitis $(1.2 \%)$, Choledocholithiasis $(1.2 \%)$, gangrene $(1.2 \%)$, epididymo-orchitis $(1.2 \%)$, osteomalacia $(1.2 \%)$, hyperthyroidism $(1.2 \%)$ and Cancer $(1.2 \%)$ as represented in (Figure 1).

\section{Systemic classification of the final diagnosis}

We have further clustered each diagnosis into specific disease categories. Circulatory disorders, endocrine disorders and respiratory disorders were the most frequent diagnosis accounting for about 34.5\% (28), $14.3 \%$ (12) and $20.2 \%$ of the elderly population admitted to the emergency, respectively. The least percentage of patients were observed in oncology, nervous disorders, ortho and others, with each having a rate of $1.2 \%$.

\section{Gender wise distribution of geriatric population into various diseases of the human system}

The most common disorders that were observed in the circulatory system were found to be myocardial infarction ( $7.2 \%$ of male), acute coronary syndrome (ACS) or coronary artery disease (CAD), cardiogenic pulmonary edema (3.6\% male), congestive cardiac failure $(14.4 \%)$ and

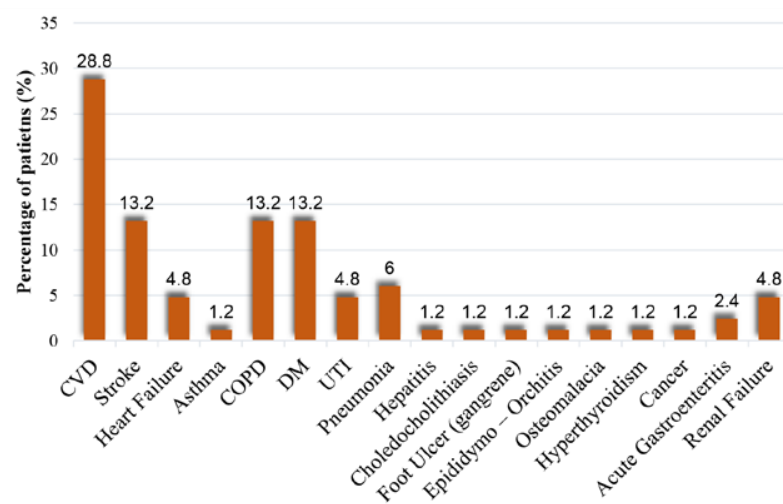

Figure 1: Final diagnosis of Elderly population.

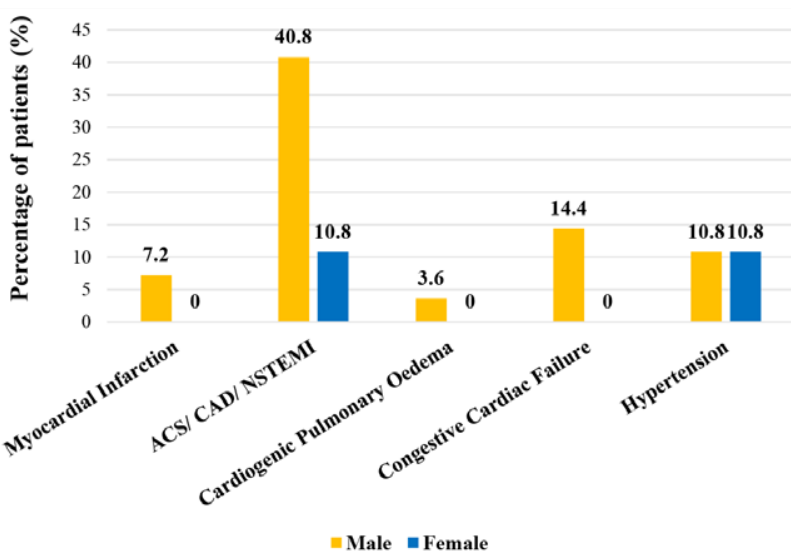

Figure 2: Circulatory System Disorders.

an equal proportion of HTN in male and female patients $(10.8 \%)$. The most common cause of admissions was ACS or CAD, which was also found to be more common in males $(40.8 \%)$ than in females $(10.8 \%)$ when analyzed by gender as represented in Figure 2 .

Whereas, COPD was found in the majority of the males $(23.5 \%)$ than in the female population $(17.6 \%)$. LRTI and Bronchitis were each diagnosed in 3 female patients that account for $17.6 \%$ of patients diagnosed with respiratory system disorders. Two male patients $(11.8 \%)$ were admitted and treated for pneumonia. The less frequent admissions were observed in respiratory failure and asthma conditions, where only one female patient was admitted $(5.9 \%)$ as represented in Figure 3. When the number of geriatric patients was categorized based on their gender, it was found that $20 \%$ of the males were diagnosed to have acute gastroenteritis and hepatitis. More females were diagnosed with GI bleed $(20 \%)$, choledocholithiasis $(20 \%)$ and GI malignancy $(20 \%)$. Amongst the study population, nine patients were found to have disorders of the genitourinary system as represented in Table 3. Out of this $33.3 \%$ male and $11.1 \%$, a female had CKD, an equal proportion of male $(22.2 \%)$ and female $(22.2 \%)$ patients had UTI and only 


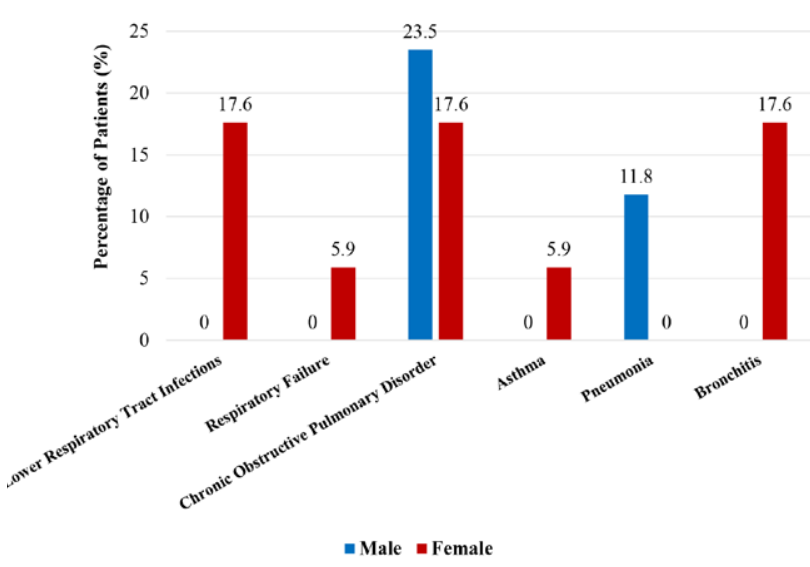

Figure 3: Respiratory System Disorder.

\begin{tabular}{ccc}
\hline \multicolumn{3}{c}{ Table 3: Genitourinary system disorder. } \\
\hline & $\%$ Male patients & $\%$ Female patients \\
\hline $\begin{array}{c}\text { Chronic Kidney } \\
\text { Disease }\end{array}$ & 33.3 & 11.1 \\
Urinary Tract Infection & 22.2 & 22.2 \\
Epididymo Orchitis & 11.1 & 0 \\
\hline
\end{tabular}

Values are expressed as percentage values for Male and Female patients for a sample of $n=9$

one male patient was admitted to receive treatment for epididymal orchitis.

$\mathrm{DM}$ is the most common endocrine disorder that affects more than 62 million Indians, as stated by the American Diabetes Association. The majority of the elderly population involved in our study were diagnosed with DM ( $50 \%$ male and $41 \%$ female). Only one case of hyperthyroidism was admitted to the ED.

Eleven patients were hospitalized with nervous disorders, with cerebrovascular accident (CVA) posing a significant threat to the patients belonging to the elderly age group. $63.6 \%$ of males and $9.1 \%$ of females were provided with treatment for CVA. The other disorders that were observed in our study were cerebral artery stroke $(9.1 \%)$, normal pressure hydrocephalus $(9.1 \%)$ and hemorrhagic infarct $(9.1 \%)$.

\section{Disposition of elderly patients in the ED}

Out of 84 patients, $16(19.2 \%)$ patients were provided with ambulatory care (Figure 4), 37 (44.4\%) patients were hospitalized for more than $24 \mathrm{hrs}, 25(30 \%)$ patients were admitted to ICU, four $(4.8 \%)$ were referred to another hospital and two $(2.4 \%)$ patients were deceased.

\section{Discharge status of elderly patients}

In the discharge status mentioned above, $2(2.4 \%)$ was

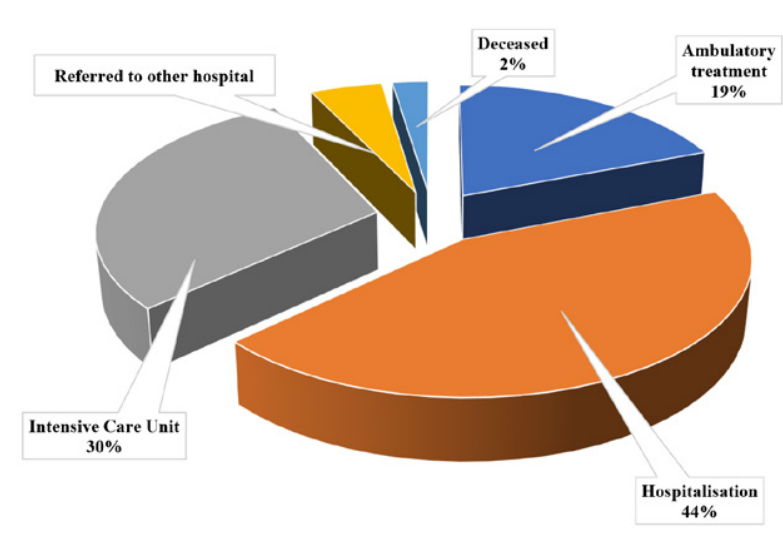

Figure 4: Disposition of Elderly Patients in ED.

discharged Against Medical Advice (AMA), 79 (94.8\%) patients were discharged, one $(1.2 \%)$ patients were removed at the request and two $(2.4 \%)$ patients died during the treatment in the ED.

\section{Polypharmacy}

From the data regarding prescriptions during the time of discharge, it was found that $74(88.5 \%)$ geriatric patients were prescribed with more than five medications and ten $(12 \%)$ patients were prescribed with less than five medications.

\section{Comorbidities}

As people get aged, it is more frequent than they have comorbid conditions, such as diabetes, renal insufficiency, arthritis, etc. In our study population, more than sixtyone $(73.2 \%)$ patients had less than three comorbidities. Whereas, twenty-three $(27.6 \%)$ patients possessed more than three comorbidities.

\section{DISCUSSION}

In developed nations, caring for elderly persons is more complicated due to factors such as low literacy rates, insecurity, inadequate family and social care, high ageing rates and shortage of social facilities, which raises admission to ED. ${ }^{30}$ In this research, we described adults over 65 years of age in the teaching hospital for urban tertiary health care and observed many parameters. Demographic factors, specifics of admission and discharge, LOS, explanations for admission to ED, final diagnosis, co-morbidity involvement, polypharmacy and final disposition were published. Our research aimed at illustrating the increasing significance of the elderly community as users of ED Services and examining the general characteristics of the aged population that account for their admission to ED. The elderly need more 
intensive treatment than younger people due to hormonal changes and chronic diseases induced by ageing. ${ }^{31}$

In this research, in all three age categories, the proportion of older male patients attending the ED was observed to be greater than that of the older female community. This findings were found to contradict other research. ${ }^{32}$ Little improvement in the conditions that gave older patients with chest pain, shortness of breath or breathlessness and abdominal and body pain were the four most frequent problems reported to be associated with Jesse M. pines et al. 2013 research..$^{32}$ Amongst all the observed reasons for admission, the most common presenting complaint was the onset of acute breathlessness or shortness of breath (32.4\%), which was similar to the reports presented by KP Abhilash et al. 2017.33

Several simultaneous diseases including pneumonia, heart failure, COPD, anaemia, HTN and is chemic heart disease can cause acute dyspnea. Other causes for elderly admissions were headache, severe gastroenteritis, temperature, decreased resistance, giddiness, burning micturition, foot colour change and diabetes treatment.

In the research performed by Unsal et al. 2003 elderly patients admitted to ED were primarily cared for HTN, cardiac and pulmonary diseases; stroke recorded by Baz. $\mathrm{U}$ et al. owing to metabolic disease, Kekec et al. observed CVD, cerebrovascular problem, heart complications such as chest discomfort, HTN. Mert et al. observed ACS, CVD and Respiratory ailments in Akpinar et al. ${ }^{34-39}$

In our research, several older patients were admitted to ED with circulatory system disorders. Especially ACS (STEMI / NSTEMI / unstable angina), CAD and HTN accompanied by patients with respiratory system disorders like COPD, metabolic disorders like DM and stroke-like cerebrovascular issues.

In our observation, just $30 \%$ of geriatric patients who came to ED came to ICUs. Chronic disease prevalence is more severe with advancing age with more recurrent and fatal cardiovascular and respiratory conditions in the elderly leading to higher admission rates and LOS. Our research showed the mortality rate was $2.4 \%$, with heart diseases being the most common cause of admission and mortality in the elderly. In many other trials, mortality was found to be higher with the same fatality reason. ${ }^{40,41}$

In their analysis, Taymaz et al. reported an estimate of $2.95 \pm 1.82$ comorbidities in the geriatric community. His analysis also showed that coronary diseases (HTN) were the most frequently seen comorbid disorders, along with $\mathrm{DM}$ and respiratory diseases, considered to be compatible with our study results. $27.6 \%$ Of the older samples used in the inclusion criterion, there were more than three comorbidities. ${ }^{42}$

Owing to decreases in functioning capacity, loss of social care, comorbidities and polypharmacy, patients over 65 years of age was correlated with higher admission rates, elevated LOS, increased resource utilisation, increased missed evaluation and higher ED ratings relative to younger adults. ${ }^{43}$

\section{CONCLUSION}

In conclusion, the hospitalisation incidence and referral rate is higher for the geriatric community relative to younger people admitted to ED. These concentrations also risen with rising age, co-morbidity and acute disease seriousness. In our research, circulatory system problems were the leading cause of entry, hospitalisation and elderly mortality. As the proportion of elderly people rises, there is a growing imperative to update ED protocols and physical formats. It calls focus to the increased need for additional solutions to better align geriatric expert programmes and frontline services. It also aids with the preparation of ED programmes for older people, which can involve geriatric case management, geriatric appraisal and renovation of the physical area of ED. It results in an emphasis on resources and instruction on common ED diagnostics for this age group.

\section{ACKNOWLEDGEMENT}

The authors thank the management and officials of Sri Ramachandra Institute of Higher Education and Research (DU) and Sri Ramachandra Medical Centre for providing us with all the facilities for the successful completion of the project.

\section{CONFLICT OF INTEREST}

There is no conflict of interest.

\section{ABBREVIATIONS}

LOS: Length of Stay; ICMR: Indian Council for Medical Research; TB: Tuberculosis; HTN: Hypertension; ED: Emergency Department; ICU: Intensive Care Unit; UTI: Urinary Tract Infection; CVD: Cardio Vascular Disease; COPD: Chronic Obstructive Pulmonary Disorder; DM: Diabetes Mellitus; ACS: Acute Coronary Syndrome; STEMI: ST-Elevation Myocardial Infarction; NSTEMI: Non-ST-elevation myocardial infarction; CAD: Coronary Artery Disease; GI: Gastro Intestinal; CKD: Chronic Kidney Disease; CVA: Cerebro vascular accident; AMA: Against Medical Advice. 


\section{REFERENCES}

1. Elderly in India-Profile and Programmes. New Delhi: Ministry of Statistics and Programme Implementation. Government of India. 2016.

2. Cabo R, LeCouteur DG. The Biology of Aging. Harrison's Principles of Internal Medicine. 19th ed. USA: McGraw-Hill Education. 2015;1-7.

3. Park JE, Park K. Textbook of social and preventive medicine. Publ Mis Banarasides Bharol. Jabalpur. 1989;594.

4. Division of geriatrics and clinical gerontology. Clinical Gerontology Branch. 2016.

5. Annual report to the people on Health. Ministry of Health and Family Welfare, Government of India. 2011.

6. Guha R. Morbidity Related Epidemiological Determinants in Indian Aged-An Overview. Public health implications of ageing in India. New Delhi: Indian Council of Medical research. 1994.

7. Purty AJ, Bazroy J, Kar M, Vasudevan K, Zacharia P, Panda P. Morbidity pattern among the elderly population in the rural area of Tamil Nadu, India. Turk J Med Sci. 2006;36(1):45-50.

8. Nair SS, Raghunath P, Nair SS. Prevalence of psychiatric disorders among the rural geriatric population: A pilot study in Karnataka, India. Cent Asian J Glob Health. 2015;4(1)

9. Gruneir A, Silver MJ, Rochon PA. Emergency department use by older adults: A literature review on trends, appropriateness and consequences of unmet health care needs. Med Care Res Rev. 2011;68(2):131-55.

10. Aminzadeh F, Dalziel WB. Older adults in the emergency department: A systematic review of patterns of use, adverse outcomes and effectiveness of interventions. Ann Emerg Med. 2002;39(3):238-47.

11. Roberts DC, McKay MP, Shaffer A. Increasing rates of emergency department visits for elderly patients in the United States, 1993 to 2003. Ann Emerg Med. 2008;51(6):769-74.

12. Li G, Lau JT, McCarthy ML, Schull MJ, Vermeulen M, Kelen GD. Emergency department utilization in the United States and Ontario, Canada. Acad Emerg Med. 2007;14(6):582-4.

13. Wofford JL, Schwartz E, Byrum JE. The role of emergency services in health care for the elderly: A review. J Emerg Med. 1993;11(3):317-26.

14. Lowthian JA, Smith C, Stoelwinder JU, Smit D, McNeil JJ, Cameron PA Why older patients of lower clinical urgency choose to attend the emergency department. Intern Med J. 2013;43(1):59-65.

15. Strange GR, Chen EH. Use of emergency departments by elder patients: A five year followup study. Acad Emerg Med. 1998;5(12):1157-63.

16. McNamara RM, Rousseau E, Sanders AB. Geriatric emergency medicine: A survey of practicing emergency physicians. Ann Emerg Med. 1992;21(7):796-801

17. Bond K, Ospina MB, Blitz S, Afilalo M, Campbell SG, Bullard M, et al. Frequency, determinants and impact of overcrowding in emergency departments in Canada: A national survey . Healthc Q. 2007;10(4):32-40.

18. Samaras N, Chevalley T, Samaras D, Gold G. Older patients in the emergency department: A review. Ann Emerg Med. 2010;56(3):261-9.

19. Salvi F, Morichi V, Grilli A, Giorgi R, DeTommaso G, Dessi-Fulgheri P. The elderly in the emergency department: A critical review of problems and solutions. Intern Emerg Med. 2007;2(4):292-301.

20. Aminzadeh F, Dalziel WB. Older adults in the emergency department: A systematic review of patterns of use, adverse outcomes and effectiveness of interventions. Ann Emerg Med. 2002;39(3):238-47.

21. Safwenberg U, Terént A, Lind L. The Emergency Department presenting complaint as predictor of in-hospital fatality. Eur J Emerg Med. 2007;14(6):324-31.
22. Lowenstein SR, Crescenzi CA, Kern DC, Steel K. Care of the elderly in the emergency department. Annals of Emergency Medicine. 1986;15(5):528-35.

23. Wofford JL, Schwartz E, Byrum JE. The role of emergency services in health care for the elderly: A review. J Emerg Med. 1993 1;11(3):317-26.

24. Baum SA, Rubenstein LZ. Old people in the emergency room: Age related differences in emergency department use and care. J Am Geriatr Soc. 1987;35(5):398-404.

25. Biber R, Bail HJ, Sieber C, Weis P, Christ M, Singler K. Correlation between age, emergency department length of stay and hospital admission rate in emergency department patients aged $\geq 70$ years. Gerontology. 2013;59(1):17-22.

26. Lowthian J, Curtis A, Stoelwinder J, McNeil J, Cameron P. Emergency demand and repeat attendances by older patients. Intern Med J. 2013;43(5):554-60.

27. Inpatient hospitalizations and emergency department visits. Canadian Institute for Health Information, Ottawa: CIHI. 2012.

28. Pines JM, Mullins PM, Cooper JK, Feng LB, Roth KE. National trends in emergency department use, care patterns and quality of care of older adults in the United States. J Am Geriatr Soc. 2013;61(1):12-7.

29. Hamel MB, Davis RB, Teno JM, Knaus WA, Lynn J, JrHarrell F, et al. Older age, aggressiveness of care and survival for seriously ill, hospitalized adults. Ann Intern Med. 1999;131(10):721-8.

30. Gutiérrez-Robledo LM. Looking at the future of geriatric care in developing countries. J Gerontol A Biol Sci Med Sci. 2002;57(3):M162-7.

31. Shah MN, Bazarian JJ, Lerner EB, Fairbanks RJ, Barker WH, Auinger P, et al. The epidemiology of emergency medical services use by older adults: An analysis of the National Hospital Ambulatory Medical Care Survey. Acad Emerg Med. 2007;14(5):441-7.

32. McCusker J, lonescu IR, Ciampi A, Vadeboncoeur A, Roberge D, Larouche D, et al. Hospital characteristics and emergency department care of older patients are associated with return visits. Acad Emerg Med. 2007;14(5):426-33.

33. Abhilash KP, Kirubairaj MA, Sahare SR. Profile of geriatric patients presenting to the emergency department. Curr Med Issues . 2017;15(3):227.

34. Ünsal A, Çevik AA, Metintaş S, Arslantaş D, İnan OÇ. Emergency department visits by elder patients. Turk J Geriatrics. 2003;6(3):83-8.

35. Baz Ü, Satar S, Kozacı N, Açıkalın A, Gülen M, Karakurt Ü. Geriatric Patien Admissions to the Emergency Service. Journal of Academic Emergency Medicine/Akademik Acil Tip Olgu Sunumlari Dergisi. 2014;13(2):53-7.

36. Kekec Z, Koc F, Buyuk S. Review of geriatric patients hospitalization in emergency department. JAEM. 2009;8(3):21-4

37. Mert E. Use of emergency departments by elderly patients. Turk J Geriatrics. 2006;9(2):70-4.

38. Akpinar O, Turkdogan KA, Kapci M, Duman A. Use of emergency department by geriatric patients. J Clin Anal Med. 2015;6:310-4.

39. Karaveli A, Cerit GN, Özyurt E. Evaluation of admission causes and mortality rates of 65 years of age and older patients admitted from the emergency department to the intensive care unit. Turk J Pediatr. 2018;21(4):515-21.

40. Aminzadeh F, Dalziel WB. Older adults in the emergency department: A systematic review of patterns of use, adverse outcomes and effectiveness of interventions. Ann Emerg Med. 2002;39(3):238-47.

41. Gray LC, Peel NM, Costa AP, Burkett E, Dey AB, Jonsson PV, et al. Profiles of older patients in the emergency department: Findings from the inter RAI Multinational Emergency Department Study. Ann Emerg Med. 2013;62(5):467-74.

42. Taymaz T. Examination of geriatric patients hospitalised from the emergency department. J Am Geriatr Soc. 2010;2(3):167-75.

43. Hajjar ER, Cafiero AC, Hanlon JT. Polypharmacy in elderly patients. Am J Geriatr Pharmacother. 2007;5(4):345-51. 